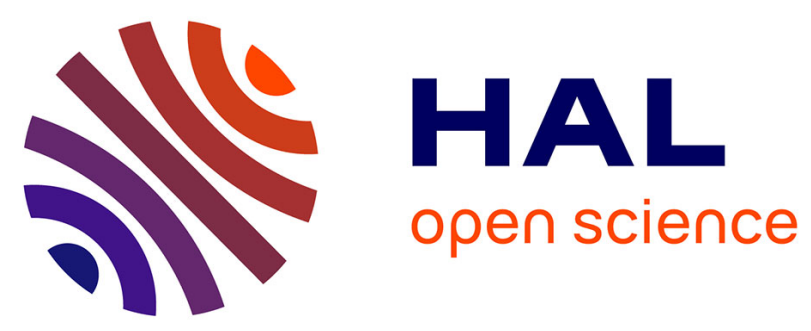

\title{
Thermal Penetration Depth Analysis and Impact of the BEOL Metals on the Thermal Impedance of SiGe HBTs
}

Rosario d'Esposito, Suresh Balanethiram, Jean-Luc Battaglia, Sebastien Fregonese, Thomas Zimmer

\section{- To cite this version:}

Rosario d'Esposito, Suresh Balanethiram, Jean-Luc Battaglia, Sebastien Fregonese, Thomas Zimmer. Thermal Penetration Depth Analysis and Impact of the BEOL Metals on the Thermal Impedance of SiGe HBTs. IEEE Electron Device Letters, 2017, 38 (10), pp.1457 - 1460. 10.1109/LED.2017.2743043 . hal-01639596

\section{HAL Id: hal-01639596 https://hal.science/hal-01639596}

Submitted on 27 Jun 2018

HAL is a multi-disciplinary open access archive for the deposit and dissemination of scientific research documents, whether they are published or not. The documents may come from teaching and research institutions in France or abroad, or from public or private research centers.
L'archive ouverte pluridisciplinaire HAL, est destinée au dépôt et à la diffusion de documents scientifiques de niveau recherche, publiés ou non, émanant des établissements d'enseignement et de recherche français ou étrangers, des laboratoires publics ou privés. 


\title{
Thermal penetration depth analysis and impact of the BEOL metals on the thermal impedance of SiGe HBTs
}

\author{
Rosario D’Esposito, Suresh Balanethiram, Jean-Luc Battaglia, Sébastien Frégonèse and Thomas Zimmer
}

\begin{abstract}
In this letter we present a detailed investigation on how dynamic thermal phenomena take place in state-of-the-art SiGe HBTs when excited by a sinusoidal power dissipation. To give a better insight into the mechanisms leading to the thermal impedance $\left(Z_{t h}\right)$ decay, we introduce the concept of thermal penetration depth; then, with the help of 3D thermal simulations, we illustrate its effect on the spatial distribution of the temperature variations within the transistor structure, according to the frequency of operation. In order to experimentally analyze the impact on a real device, dedicated HBT structures are designed; they consist of multi-finger SiGe HBTs realized in B55 technology from STMicroelectronics, for which modifications are made in the Back-End-Of-Line (BEOL) metallization or in the transistor layout, increasing its Deep Trench Isolation (DTI) enclosed area. For these transistors, $Z_{\text {th }}$ measurements are carried out in the frequency range $10 \mathrm{kHz}-1 \mathrm{GHz}$; the results show that the metal connections configuration in the BEOL or layout modifications can considerably impact the $Z_{\text {th }}$ decay at low frequencies. An identical $Z_{\text {th }}$ trend is instead measured above 1-2 $\mathrm{MHz}$, demonstrating that at higher frequencies just the region close to the heat source is concerned by dynamic thermal phenomena.
\end{abstract}

Index Terms-SiGe HBT, thermal penetration depth, thermal impedance, BEOL metals thermal impact, thermal capacitance

\section{INTRODUCTION}

$\mathrm{T}$ hermal effects are one of the key factors limiting the performance and reliability of devices and integrated circuits realized using SiGe HBT technologies, in which the continuous trend to shrink the device dimensions leads to critically high power densities [1], [2]; in addition, the adoption of shallow and deep trench isolations, filled with low thermal conductivity materials, limits the lateral heat diffusion, and thus contributes to increase the devices $\mathrm{R}_{\mathrm{th}}$. Due to the strong relationship between electrical and temperature effects in these components [3], which is worsened by their positive feedback [4], a realistic and physics-based thermal compact modeling is mandatory; a reliable compact model must ensure accurate circuit simulations during the design phase [5], [6], which take into account the operating temperatures of the HBTs. In stateof-the-art SiGe HBTs thermal phenomena arise when a static power dissipation $\left(\mathrm{P}_{\text {diss }}\right)$ is applied, but also when the devices

Manuscript received July 22, 2017; revised August 9, 2017. Date of publication September xx, 2017. This work is funded by the French Public Authorities through NANO 2017 and by the EU, through Project Taranto (No. 737454). The review of this letter was arranged by Editor Prof. Lis Nanver.

Rosario D'Esposito, Suresh Balanethiram, Sébastien Frégonèse and Thomas Zimmer are with the IMS Laboratory, University of Bordeaux, Talence 33405, France. (e-mail: rosario.desposito@gmail.com).

Jean-Luc Battaglia is with the TREFLE Laboratory, ENSAM Department of Mechanics, University of Bordeaux, Talence 33405, France

Color versions of one or more of the figures in this letter are available online at http://ieeexplore.ieee.org.

Digital Object Identifier xyxyxyxyx are operated in dynamic conditions, since their thermal bandwidth is within few hundreds of $\mathrm{MHz}$ [7], [8]. Many works can be found in literature about DC self-heating effects [4], [9][11], but less attention is given to dynamic thermal modeling. It must be considered, though, that when the HBTs are driven by a signal having a bandwidth within their thermal constant, due to the intrinsic transistor nonlinearities, third-order intermodulation products (IMD3) arise and can trigger low frequency (LF) variations of the junction temperature, which can significantly affect the electrical behavior of the component [12], [13]. A deep understanding of the thermal mechanisms taking place in sinusoidal operation and a precise characterization of the $Z_{\text {th }}$ are therefore necessary to obtain a realistic thermal model, which can result very helpful in certain applications, like the design of pre-distortion linearizers for power amplifiers [14]-[16].

In this letter we present a detailed investigation on how dynamic thermal phenomena take place in state-of-the-art SiGe HBTs, by introducing the concept of thermal penetration depth. 3D thermal simulations are reported in section II, which gives an alternative insight into these physical mechanisms; in section III different sets of dedicated transistor structures are presented and their $\mathrm{Z}_{\mathrm{th}}(\mathrm{f})$ are compared; to our knowledge no previous study on the BEOL has been supported by $Z_{t h}$ measurements.

\section{THERMAL PENETRATION DEPTH SIMULATIONS IN 3D TCAD}

To have an alternative insight into the dynamic spreading of the heat within the transistor structure, we can consider a very simplified case of study: let us assume a semi-infinite silicon block having an initial uniform temperature $\mathrm{T}_{0}$. When a uniformly distributed $\mathrm{P}_{\text {diss }}$ is applied at one side, eventually the whole block of material will tend to reach a higher temperature $\mathrm{T}_{1}$. But before this happens, a thermal gradient can be observed within a certain distance from the heat source, while beyond this boundary the temperature of the block is still $\mathrm{T}_{0}$. The thermal penetration depth $(\delta)$ is defined as the distance that the heat diffuses through the material (under a sinusoidal stimulus) during a time $1 / f$ and is approximated with the expression [17]:

$$
\delta=\sqrt{\frac{k}{c \rho \pi f}}
$$

where $f$ is the $\mathrm{P}_{\text {diss }}$ frequency, whereas $k c$ and $\rho$ are, respectively, the thermal conductivity, specific heat and density of the material. Note that (1) is only valid in $1 \mathrm{D}$ heat transfer by conduction; moreover it must be considered that a state-of-theart SiGe HBT has a complex structure, made of multiple material layers, having very different thermal properties.

Nevertheless, (1) indicates the general trend that should be 


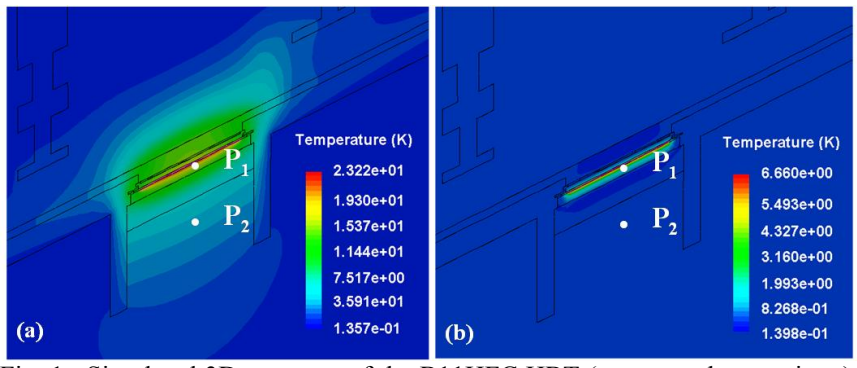

Fig. 1. Simulated 3D structure of the B11HFC HBT (zoom on the transistor), showing the thermal penetration depth $(\delta)$ profile. A sinusoidal power having a frequency of $50 \mathrm{kHz}$ (a) and $100 \mathrm{MHz}$ (b) are applied at the $\mathrm{BC}$ junction.
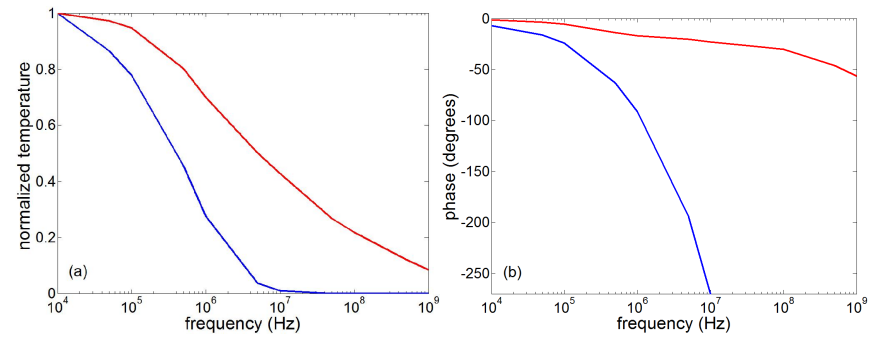

Fig. 2. Normalized amplitude (a) and phase (b) of the temperature oscillations in $\mathrm{P}_{1}$ (red) and $\mathrm{P}_{2}$ (blue) versus $\mathrm{P}_{\text {diss }}$ frequency $\left(\mathrm{P}_{\mathrm{DC}}=40 \mathrm{~mW}, \mathrm{P}_{\mathrm{AC}}=2 \mathrm{~mW}\right)$.

expected; in particular, since $\delta$ is inversely proportional to $\sqrt{f}$, the volume of the silicon that effectively contributes to $Z_{\text {th }}$ reduces if the frequency increases. To show this behavior and understand how the induced temperature variations will penetrate in the transistor, 3D thermal simulations using Sentaurus TCAD have been performed on the transistor structure in Fig. 1 representing an HBT from the Infineon $\mathrm{B} 11 \mathrm{HFC}$ technology $\left(\mathrm{A}_{\mathrm{E}}=5 \mathrm{x} 0.2 \mu \mathrm{m}^{2}\right)$. In these simulations the thermal conductivity degradation due to high doping is taken into account, according to experimental data in [18] and [19]. A planar heat source (HS) is placed at the base-collector (BC) junction and isothermal conditions are applied at the back surface of the wafer and at the top, above a $15 \mu \mathrm{m}$ thin air layer acting as a laminar sub-layer, in which just conduction can be considered [20]; due to the very low $k$ of air $(0.024 \mathrm{~W} / \mathrm{mK})$ this boundary condition is very close to be adiabatic. Sinusoidal power stimuli are applied to the HS, at frequencies ranging from $10 \mathrm{kHz}$ to $1 \mathrm{GHz}$.

In Fig. 2 are plotted the normalized amplitude and the phase of the simulated temperature oscillations, for two different positions $\mathrm{P}_{1}$ and $\mathrm{P}_{2}$ (respectively $80 \mathrm{~nm}$ and $6.38 \mu \mathrm{m}$ below $\mathrm{HS}$ ). It can be observed that their amplitude will tend to reduce if the frequency is increased, due to the intrinsic thermal capacitance $\left(\mathrm{C}_{\mathrm{th}}\right)$ of the structure. Moreover if the distance from the HS is higher, oscillations will tend to disappear; in fact in $\mathrm{P}_{1}$ significant oscillations $(20 \%$ of the temperature variations simulated at DC) are visible till a frequency of $100 \mathrm{MHz}$, whereas the same relative amplitude is already reached at $1 \mathrm{MHz}$ in point $\mathrm{P}_{2}$. The absolute value of the thermal oscillations is $20^{\circ} \mathrm{C}$ in $\mathrm{P}_{1}$ and $0.9^{\circ} \mathrm{C}$ in $\mathrm{P}_{2}$ at a frequency of $10 \mathrm{kHz}$.

It can be also noticed that the phase shift will increase if the frequency of the $\mathrm{P}_{\text {diss }}$ increases; furthermore in $\mathrm{P}_{2}$ the phase shift becomes more evident, since the distance from the heat source is higher than in $\mathrm{P}_{1}$ and thus a longer time is needed for the thermal variations induced from the HS to travel through the
HBT structure. If instead we fix a frequency and have a look at the distribution of the amplitude of the thermal oscillations within the transistor, we will have a direct image of the spatial distribution of $\delta$. As reported in Fig. 1, at $100 \mathrm{MHz}$ the thermal variations are only visible in a small volume around the BC.

\section{THERMAL PENETRATION DEPTH EXPERIMENTAL STUDY}

To investigate how the thermal oscillations induced by a sinusoidal power dissipation affect the behavior of a real transistor and to estimate the penetration depth inside the component, dedicated test structures need to be designed. If a sinusoidal $\mathrm{P}_{\text {diss }}$ is applied, as shown in the previous section, temperature oscillations are induced in the lower part of the HBT, but, of course, they are also present in the BEOL. It is therefore possible to study these thermal penetration phenomena by characterizing and comparing the thermal behavior of transistor structures in which the lower part of the device is kept unaltered, whereas modifications are made in the $\mathrm{BEOL}$ region (during the design there is in fact a certain degree of freedom on the geometry of the different metal layers).

The HBTs under study in this work consist of five-fingers SiGe HBTs realized in STMicroelectronics B55 technology, of which a complete thermo-electrical characterization has been reported in [21]; in this section we will further extend our study, showing the thermal impedance extracted from LF S-parameter measurements in the range $10 \mathrm{kHz}-1 \mathrm{GHz}$. In particular, we will now focus on the set of test structures named VM, for which copper metal dummies, acting as heat spreaders, are present upon the emitter contacts till metal-3 (VM3), metal-6 (VM6) and metal-8 (VM8); in a reference transistor named VM1 the metallization on the emitter contacts stops instead at metal-1 level (refer to Fig.3). It must be pointed out that the $\mathrm{R}_{\text {th }}$ value of these transistors is lowered as higher levels are reached for the metallization in the BEOL [22]-[24], since the heat flux can find an alternative path in the copper of the BEOL (the results for the $\mathrm{R}_{\mathrm{th}}$ of these HBTs are detailed and reported in [21]).

An accurate design of the metal connections can thus lead to improved SOA specifications [21] and better RF performances [22]. Moreover, as it is suggested by equation (1), $\delta$ is inversely proportional to the square root of the $\mathrm{P}_{\text {diss }}$ frequency, which means that, at low frequencies, the thermal oscillations can significantly penetrate the structure, both downwards (towards the back of the wafer) and upwards, till eventually reaching the higher levels of the metal in the BEOL. In this scenario, the different $Z_{\text {th }}$ trend observed at LF among the HBTs under study (Fig. 4), is due to the fact that $\delta$ has reached a distance within the abscissas of the metal dummies, and so transistors having heat spreaders till higher levels of metal will exhibit a lower $Z_{\text {th }}$. In the high frequency range, instead, all the VM transistors show an identical $Z_{\text {th }}$ decay, in fact the thermal oscillations will tend to be confined in close proximity to the heat source as the frequency increases; since within this region all the transistor structures are identical (Fig.3), their $Z_{\text {th }}$ will be the same.

From a physical modelling point of view, at low frequencies, temperature oscillations will interest a considerable volume of silicon around the HS, so it can be considered that high valued $\mathrm{C}_{\mathrm{th}}$ are thermally charged and discharged. It is in fact possible 


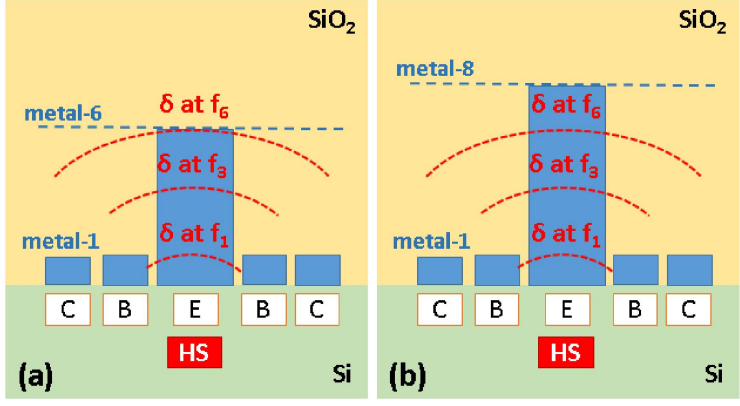

Fig. 3. Representation of the VM6 (a ) and VM8 (b) transistors, showing the different levels of metal dummies and the $\delta$ at different frequencies

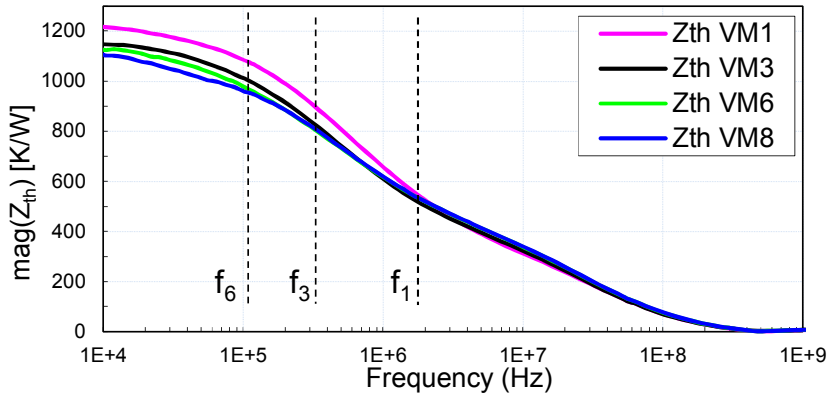

Fig. 4. Extracted $Z_{\text {th }}$ versus frequency for the VM test structures.

to take into account the presence of the copper dummies in the VM transistors by adding big thermal capacitances in parallel to the thermal network of the lower part of the transistor [25]. These added $\mathrm{C}_{\text {th }}$ determine the thermal behavior at LF, but, as the frequency increases, the overall big volume of copper in the BEOL cannot participate to the temperature oscillations, due to its intrinsic thermal inertia; the AC dynamic phenomena can be rather approximated to happen in a small portion of silicon surrounding the $\mathrm{BC}$ junction.

It is interesting to notice, observing Fig. 4, that going from the highest frequencies (where all the VM transistors exhibit an identical $Z_{\text {th }}$ trend) towards the lowest, we can identify a frequency $\mathrm{f}_{1}$ (around $2 \mathrm{MHz}$ ) starting from which the $Z_{\text {th }}$ of VM1 starts to deviate from the others. This means that, at $f_{1}$ the thermal penetration depth has reached the abscissa corresponding to metal-1; the same assumption can be made as the frequency decreases, and it is also possible to identify $f_{3}$ and $\mathrm{f}_{6}$, where $\delta$ reaches respectively the levels 3 and 6 of metallization. The set of test structures under study in [21] also allows an investigation of the penetration depth in the horizontal plane: the thermal diffusion phenomena under study have in fact an isotropic nature. Among the structures presented in [21], the transistor named HL1 contains metal connections reaching the same level as VM3, but has an increased Deep Trench Isolation (DTI) enclosed area. HL1 thus allows a wider angle for the lateral heat spreading, which in turn ensures a better evacuation of the heat generated from the HS towards the silicon substrate, yielding a lower $\mathrm{R}_{\mathrm{th}}[21]$.

Comparing the $\mathrm{Z}_{\text {th }}$ of the HL1 and VM3 transistors shown in Fig. 5 , it is again noticed that increasing the DTI enclosed area yields a decrease in the $Z_{\text {th }}$ at low frequency. At higher frequencies, though, it is just the volume in close proximity of the HS that determines $Z_{\text {th }}$, and it can be supposed that, in this situation, the thermal variations do not reach the DTI, which

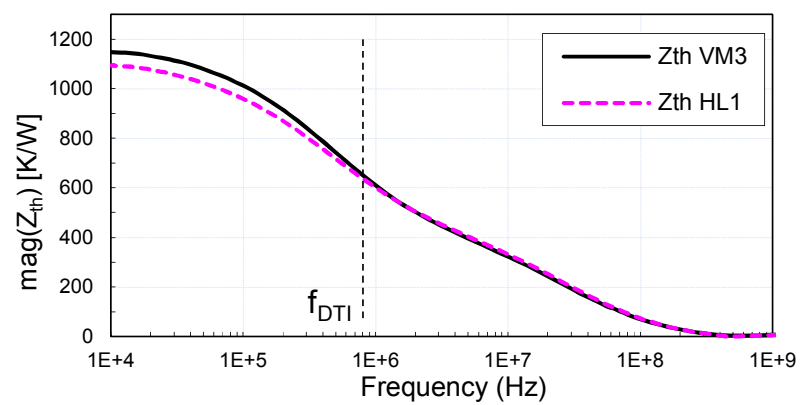

Fig. 5. Extracted $Z_{\text {th }}$ versus frequency for the HL1 and VM3 transistors.

restricts the heat flux. The condition that thermally favors HL1 does not hold any more, and the two structures tend to behave the same way for frequencies higher than around $1 \mathrm{MHz}$ ( $\mathrm{f}_{\mathrm{DTI}}$ in Fig. 5), where we can assume that $\delta$ has reached, in the horizontal plane, the adiabatic wall represented by the DTI.

\section{CONCLUSIONS}

In this letter we have shown, by means of thermal 3D simulations and reporting $Z_{\text {th }}$ measurements on specially designed transistor structures, how dynamic thermal mechanisms take place in SiGe HBTs from state-of-the-art technology nodes; in principle, though, similar thermal phenomena also take place in devices implemented in other technologies.

We demonstrated how, at different operating frequencies, the thermal impedance influences the spatial distribution of the temperature fluctuations within the transistor structure: at high frequencies, sinusoidal temperature variations are still present, even if they tend to be confined in the region close to the HS.

In the experimental part it has been shown how a specially conceived set of DUTs can allow to identify the frequencies at which the temperature oscillations imposed by a sinusoidal $P_{\text {diss }}$ reach a certain distance from the HS. This can be of interest in the development of physical thermal models for the $Z_{\mathrm{th}}$; the measured $Z_{\text {th }}(\mathrm{f})$ decays reported, in fact, clearly show a distributed nature. It is therefore strongly recommended to use at least a three poles network (instead of a single pole normally used in compact models) to accurately take into account dynamic thermal effects in the low frequency range. This is particularly important in circuit designs where IMD3 products arise within the thermal bandwidth of the HBTs.

Besides it is experimentally demonstrated that the configuration of materials in the BEOL, although far from the HS, has a non-negligible thermal impact: in particular the presence of metal connections can considerably affect the $Z_{\text {th }}$ decay at LF. In the same way, if the transistor layout is altered, (e.g. enlarging the DTI enclosed area) $Z_{\text {th }}$ variations should be rather present in theLF range, but it must be pointed out that instead at frequencies starting from around 1-2 $\mathrm{MHz}$ the same $\mathrm{Z}_{\mathrm{th}}$ trend has to be expected, regardless of any modifications of the HBT structure in the vertical or horizontal plane.

\section{V.ACKNOWLEDGMENTS}

The authors would like to thank STMicroelectronics for providing the B55 wafer used for the experimental characterization of the HBTs. 


\section{REFERENCES}

[1] M. Schröter and A. Chakravorty, Compact Hierarchical Bipolar Transistor Modeling with HiCuM, World Scientific. 2010. ISBN: 978-981-4273-21-3

[2] P. Chevalier, M. Schröter, C. R. Bolognesi, V. d'Alessandro, M. Alexandrova, J. Böck, R. Flückiger, S. Fregonese, B. Heinemann, C. Jungemann, R. Lövblom, C. Maneux, O. Ostinelli, A. Pawlak, N. Rinaldi, H. Rücker, G. Wedel, T. Zimmer, "Si/SiGe:C and InP/GaAsSb Heterojunction Bipolar Transistors for THz Applications," in Proceedings of the IEEE, vol. 105, no. 6, pp. 1035-1050, June 2017. doi: 10.1109/JPROC.2017.2669087

[3] H. Kamrani, D. Jabs, V. d'Alessandro, N. Rinaldi, K. Aufinger and C. Jungemann, "A Deterministic and Self-Consistent Solver for the Coupled Carrier-Phonon System in SiGe HBTs," in IEEE Transactions on Electron Devices, vol. 64, no. 2, pp. 361-367, Feb. 2017. doi: 10.1109/TED.2016.2640343

[4] N. Rinaldi and V. d'Alessandro, "Theory of electrothermal behavior of bipolar transistors: Part I -single-finger devices," in IEEE Transactions on Electron Devices, vol. 52, no. 9, pp. 2009-2021, Sept. 2005. doi: 10.1109/TED.2005.854274

[5] M. T. Ozalas, "The Impact of Electro-Thermal Coupling on HBT Power Amplifiers," 2014 IEEE Compound Semiconductor Integrated Circuit Symposium (CSICS), La Jolla, CA, 2014, pp. 1-4. Oct. 2014. doi: 10.1109/CSICS.2014.6978582

[6] V. d'Alessandro, N. Rinaldi, A. G. Metzger and H. M. Banbrook, "On the safe operating area of bipolar cascode amplifiers," 2013 IEEE Bipolar/BiCMOS Circuits and Technology Meeting (BCTM), Bordeaux, Sept. 2013, pp. 171-174. doi: 10.1109/BCTM.2013.6798168

[7] I. Hasnaoui, A. Pottrain, D. Gloria, P. Chevalier, V. Avramovic and C. Gaquiere, "Self-Heating Characterization of SiGe:C HBTs by Extracting Thermal Impedances," in IEEE Electron Device Letters, vol. 33, no. 12, pp. 1762-1764, Dec. 2012. doi: 10.1109/LED.2012.2220752

[8] A. El Rafei, A. Saleh, R. Sommet, J. M. Nebus and R. Quere, "Experimental Characterization and Modeling of the Thermal Behavior of SiGe HBTs," in IEEE Transactions on Electron Devices, vol. 59, no. 7, pp. 1921-1927, July 2012. doi: 10.1109/TED.2012.2196765

[9] S. Balanethiram, A. Chakravorty, R. D'Esposito, S. Fregonese and T. Zimmer, "An improved scalable self-consistent iterative model for thermal resistance in SiGe HBTs," 2016 IEEE Bipolar/BiCMOS Circuits and Technology Meeting (BCTM), New Brunswick, NJ, Sept. 2016, pp. 150-153. doi: 10.1109/BCTM.2016.7738953

[10] M. Pfost, V. Kubrak and P. Brenner, "A practical method to extract the thermal resistance for heterojunction bipolar transistors," European Solid-State Device Research, 2003. ESSDERC '03. 33rd Conference on, Estoril, Portugal, Sept. 2003, pp. 335-338. doi: 10.1109/ESSDERC.2003.1256882

[11] V. d'Alessandro, G. Sasso, N. Rinaldi, and K. Aufinger, "Influence of Scaling and Emitter Layout on the Thermal Behavior of Toward-THz SiGe:C HBTs," IEEE Transactions on Electron Devices, vol. 61, no. 10, pp. 3386-3394, Oct. 2014. doi: 10.1109/TED.2014.2349792

[12] R. Ishikawa, J. Kimura and K. Honjo, "Analytical Design Method for a Low-Distortion Microwave InGaP/GaAs HBT Amplifier Based on Transient Thermal Behavior in a GaAs Substrate," in IEEE Transactions on Components, Packaging and Manufacturing Technology, vol. 3, no. 10, pp. 1705-1712, Oct. 2013. doi: 10.1109/TCPMT.2013.2262504

[13] V. Camarchia, F. Cappelluti, M. Pirola, S. D. Guerrieri and G. Ghione, "Self-Consistent Electrothermal Modeling of Class A, AB, and B Power GaN HEMTs Under Modulated RF Excitation," in IEEE Transactions on Microwave Theory and Techniques, vol. 55, no. 9, pp. 1824-1831, Sept. 2007. doi: 10.1109/TMTT.2007.903839

[14] Y. Takahashi, R. Ishikawa and K. Honjo, "Precise modeling of thermal memory effect for power amplifier using multi-stage thermal RC-ladder network," 2006 Asia-Pacific Microwave Conference, Yokohama, Dec. 2006, pp. 287-290. doi: 10.1109/APMC.2006.4429424

[15] J. H. K. Vuolevi, T. Rahkonen and J. P. A. Manninen, "Measurement technique for characterizing memory effects in RF power amplifiers," in IEEE Transactions on Microwave Theory and Techniques, vol. 49, no. 8 , pp. 1383-1389, Aug 2001. doi: 10.1109/22.939917

[16] W. Bosch and G. Gatti, "Measurement and simulation of memory effects in predistortion linearizers," in IEEE Transactions on Microwave Theory and Techniques, vol. 37, no. 12, pp. 1885-1890, Dec 1989. doi: $10.1109 / 22.44098$

[17] A. Salazar, "Energy propagation of thermal waves," Eur. J. Phys., vol. 27, no. 6, p. 1349, Jun. 2006. https://doi.org/10.1088/0143-0807/27/6/009
[18] W. Liu, K. Etessam-Yazdani, R. Hussin and M. Asheghi, "Modeling and Data for Thermal Conductivity of Ultrathin Single-Crystal SOI Layers at High Temperature," in IEEE Transactions on Electron Devices, vol. 53, no. 8, pp. 1868-1876, Aug. 2006. doi: 10.1109/TED.2006.877874

[19] A. D. McConnell, S. Uma and K. E. Goodson, "Thermal conductivity of doped polysilicon layers," in Journal of Microelectromechanical Systems, vol. 10, no. 3, pp. 360-369, Sep 2001. doi: 10.1109/84.946782

[20] S. Kaka and Y. Yener, Convective Heat Transfer, Second Edition, CRC Press. 1995. ISBN: 9780849399398

[21] R. D’Esposito, S. Frégonèse, A. Chakravorty, P. Chevalier, D. Céli and T. Zimmer, "Innovative SiGe HBT Topologies With Improved Electrothermal Behavior," in IEEE Transactions on Electron Devices, vol. 63 , no. 7 , pp. 2677-2683, July 2016. doi: 10.1109/TED.2016.2570601

[22] R. D’Esposito, M. De Matos, S. Fregonese, S. Balanethiram, A. Chakravorty, K. Aufinger and T. Zimmer, "Influence of the BEOL Metallization Design on the Overall Performances of SiGe HBTs," in 2016 13th IEEE International Conference on Solid-State and Integrated Circuit Technology (ICSICT), Hangzhou, China, Oct. 2016. doi: 10.1109/ICSICT.2016.7998920

[23] A. D. D. Dwivedi, A. Chakravorty, R. D’Esposito, A. K. Sahoo, S. Fregonese, and T. Zimmer, "Effects of BEOL on self-heating and thermal coupling in SiGe multi-finger HBTs under real operating condition," Solid-State Electronics, Volume 115, 2016, Pages 1-6, ISSN 0038-1101, http://dx.doi.org/10.1016/j.sse.2015.09.016.

[24] V. d'Alessandro, A. Magnani, L. Codecasa, N. Rinaldi, K. Aufinger, "Advanced thermal simulation of SiGe:C HBTs including back-end-ofline", Microelectronics Reliability, Volume 67, 2016, Pages 38-45, ISSN 0026-2714, http://dx.doi.org/10.1016/j.microrel.2016.06.005

[25] R. D’Esposito, S. Fregonese, T. Zimmer, and A. Chakravorty, "Dedicated test-structures for investigation of the thermal impact of the BEOL in advanced SiGe HBTs in time and frequency domain," in 2016 International Conference on Microelectronic Test Structures (ICMTS), 2016, pp. 28-31. doi: 10.1109/ICMTS.2016.7476168 